\section{RESPONSE TO NELSON'S "XENOGRAFT AND PARTIAL AFFECTIONS"}

\author{
CONNIE KAGAN \\ A.N.P.A.C.
}

Jim, I think you have presented us with a thought-provoking and very ambitious paper. I think you have confronted a problem which we all know very well, which is that we really need 400 pages for what we have to say but are 1 irited to 16 , and as a consequence, some of the detail, the explanations, the thoroughness that we want just cannot be there. So, what I will do is make some comments and raise a few questions about some of the major points in the paper in order to allow us to take a closer look at then.

I want to begin by sumarizing what I understand to be the major thrust of your. arguments. The thesis is that parental partiality justifies xenograft. You put it in very plain English. You say, "The answer to the question, Is xenograft imoral? depends on who is asking. If the question is put on behalf of parents struggling to save their child's life, the answer, as best I can see, is No."

So you then take upon yourself two tasks: (1) showing why parental partiality is preferable to other moral stances--including impartial reason, species partiality, utilitarianism, or a theory of rights--and (2) the task of showing how parental partiality justifies xenograft. I want to comment first on a few points you make in comparing parental partiality to other moral stances.

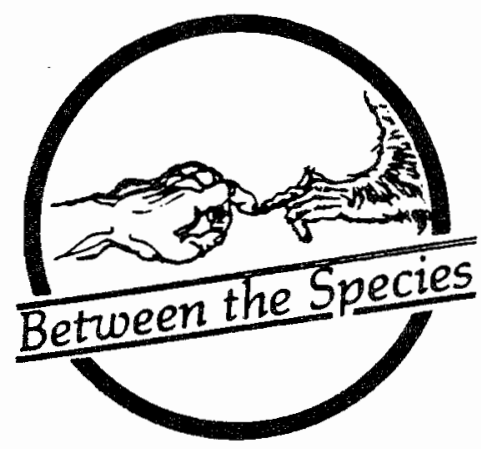

You point out that utilitarianism, which clains impartiality, may be impartial in the application but not in its assignment of relative values to humans and non-humans. I think this is a very important point that often gets overlooked. It is fine and good to include animals--more accurately, some species of animals--in the moral community, so that their interests will be taken into account in making moral decisions. But, in the distribution of utilities and even more so in the distribution of disutilities, the animals lose. They lose precisely because of the assumptions about the comparable worth or value of humans and animals. The usual assumption or determination is that human life is more valuable than animal life according to scme criterion or other, and therefore the general good of the community is increased by letting the animals suffer for the sake of the humans.

I think your description of this partiality in utilitarianism is exactly right, and I am glad you pointed it out. I agree with you that that happens.

I do not agree, however, with your discussion about the comparable worth problemthe difficulties of comparing human and animal life-and where the difficulties in that problem leave us. You say that because there are facts about the subjective experiences of animals which we do not know and cannot know -what it is like to be a dog or a dolphin, for example-that "we have no reason for holding that our experiences are more significant than those open to animals, but neither will we have any reason for thinking that theirs are equal or greater in significance than ours." Then you add, "If this is what we are stuck with, then it seems that there are no good reasons to move us off our species partialities." In other words, since we do not know and cannot know the subjective experiences of other species, we might as well be partial to our own species.

First of all, it is not clear why that would follow, how ignorance about other species implies the justifiability of partiality for our own species. But more importantly, I do not think it is true that we are so ignorant. What we know and can know about the subjective experiences of other animals are

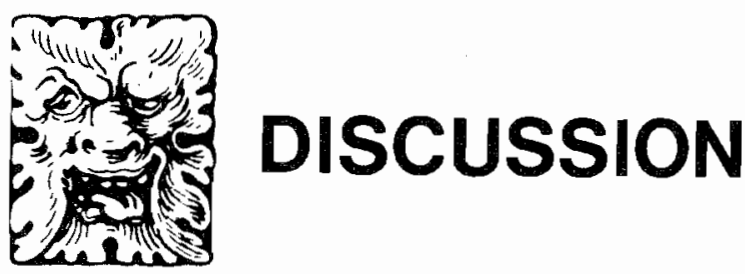


epistemological concerns. As an epistemologist, there is nothing I would like better than to spend several hours telling you why I think we do know and can know about the subjective experiences (or mental states) of some other animals. But, since I have only a few minutes, I will just briefly say first that I think we have to consider what we can know about subjective experiences of animals on a species by species basis. There are epistemologically relevant differences among species that necessitate our considering questions about mental states species by species.

In the case of xenograft, we are talking about the use of primates, including chimpanzees because of their physiological similarity to humans. That similarily is one reason we can know sonething about the mental states (such as pain) of chimpanzees, for example. Given the similarity of human and chimpanzee physiology, including neurophysiology, we can do what we do in the case of other humans, wich is to make inferences about others' pain by analogy to our own case. There are good reasons to believe that chimpanzees' experiences of pain are very similar to humans' experiences of pain. Furthermore, with chimpanzees and gorillas, we know something about their subjective experiences because they have told us. Washoe and koko are good examples of primates who have described their own subjective experiences for us.

But I want to hasten to add that while I think we can and do know something about the subjective experiences of some other animals, I do not think we ought to purse that knowledge for the purpose of determining the comparative worth of humans and animals. I think we need to break the bonds of the value-laden hierarchical, Aristotelian Chain of Being.

And I agree with you that Tom Regan is on the right track with the view that it is not the content of animal experiences that matters but the fact that animals "are 'subjects of a life' which has value independently of its value to us."

Now, with regard to your second major task-showing how parental partiality justifies xenograft--I have some questions about the arguments.

The first argument is that choosing xenograft is justifiable because it is a life or death matter for the child and there are no alternatives. "The parent has little real choice if she is to save her child."

I think we have to make some distinctions here between types of transplants. There are situations in which a child might need an organ and the need would not be a life or death crisis. For example, an older child might need a kidney. The better alternative for the child might be for the parent to donate a kidney, since the genetic similarity would increase chances for a successful transplant.

But let us suppose our case is the one where an infant needs a new heart. Is choosing xenograft justifiable because it is a life or death matter and there are no alternatives? You think it is because xenograft will save the child's life, but that is false. Xenograft does not save children. Xenograft temporarily prolongs the lives of children under very difficult circumstances, but it does not save the lives of children.

You quite rightly acknowledge this in your statement about Baby Fae. You say, "It's far from clear that xenograft actually served any of Fae's interests, or that it was even very reasonable to believe it might; she may have been as much an experimental animal as Goobers, her donor." That is an accurate statement about the primitive state of lifecritical xenograft. It does not now save children's lives, and any decision made on the false assumption that it does is not a good decision.

But then you think about the future. You say, "It is perfectly reasonable to think that interspecies transplantation could come to be a technique of real value to many otherwise doomed children."

I have two concerns about this. First, it may be factually false. There is one school of thought among cardiac specialists that the greatest advances will come from improved technological development of artificial hearts, not from any kind of transplantation.

But what if that is wrong, and xenograft might turn out to be of real value? The question this poses is: how do we get from here to there? Xenograft is not now of real value for doomed children. If you believe in parental partiality, then parents ought not to volunteer their children to be experimen- 
ted on in the hope that it might help some other children in the future. So, it would seem that you cannot morally get there fram here.

The second argument intended to show that parental partiality justifies renograft says that if you refuse to use the animal's heart, it will cost the child's life but may not save the animal's life.

It is true that your decision not to use an animal's heart probably will not save the life of the animal. The animal in an organ donor lab will die if your child gets his/her heart; he/she may not die otherwise, though he/she probably will. But it is not true, as the argument implies, that you are choosing between a child's life and an animal's life. The child will die if he/she gets the animal's heart, and he/she will die if he/she does not.

The third argument is that death is a greater harin to a child than to a baboon. Once again, what is implied is that one is making a choice between the child's life and the baboon's life which, as I have just shown, is not the case. For that reason, any assumptions about comparable worth are moot.

The fourth argument is this; If a parent rejects xenograft, he/she has sacrificed parental partiality to impartial reason, but if a parent accepts xenograft, he/she can have it both ways, because he/she can exercise parental partiality through xenograft and impartiality by individually pushing for reform in medical research.

This does not seem to me to be an argument to show that parental partiality justifies xenograft. Rather, it is a meta-argument for philosophers interested in moral and logical consistency. It is clever, but I do not think it is gernane to the question whether parental partiality justifies xenograft.

In conclusion, then, I do not think a good parent would choose xenograft for his/ her child. Given the fact that xenograft is not a life-saving alternative and given a parent's responsibility to protect his/her child from unnecessary harm, I think a good parent would not choose xenograft for his/her child. The choice of xenograft would be immoral because it would cause unnecessary pain and suffering for the child and unnecessary death for the animal.
CONCERNING THERAPEUTIC (FOR HUMANS) RESEARCH WITH ANIMALS: A RESPONSE TO NELSON'S “XENOGRAFT AND PARTIAL AFFECTIONS"

\author{
STEVE F. SAPONTZIS \\ California State University, Hayward
}

As Jim Nelson correctly and poignantly indicates, even those who are deeply concerned about the moral respect due animals and who are actively trying to eradicate the human abuse of animals can feel that they are confronting a moral dilemma when confronting uses of animals which seem obviously beneficial for the health and even the very life of humans. This is especially true when those humans are, like children, dependent on them for their care and well-being. Any moral theory which failed to recognize that there is a morally significant difference between such cases and cases where animals are exploited for marginal or trivial purposes---as in rodeos, sport hunting, gourmet cooking, and a great deal, if not all, psychological research employing animals--could justifiably be considered doctrinaire. Discovering what ought to be done in such cases requires untying a tough knot, not slicing through it. This is, I take it, what Nelson is about in his paper.

The cornerstone of Nelson's argument is that parents are morally justified in giving preference to their children over others. I would not dispute that; I think that any moral theory which would have us deal with all sentient beings on a thoroughly irmpartial, egalitarian basis is not only thoroughly impractical but also unwarranted and undesirable. However, as Nelson recognizes, there are moral limits to what parents may do for their children. That one needed the money to pay for his/her child's education would not justify his/her stealing and cashing a neighbor's winning lottery ticket. So, further reasons, beyond parents' affection

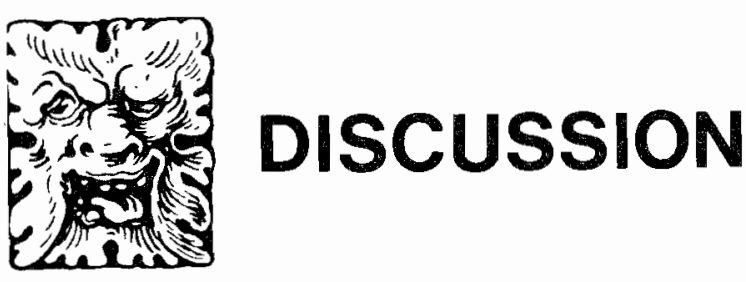

